\title{
In-situ grain structure and texture evolution during friction stir welding of austenite stainless steel
}

\author{
F.C. Liu ${ }^{*}$, and T.W. Nelson ${ }^{*}$ \\ Department of mechanical engineering, Brigham Young University, Provo, UT 84602, USA
}

\begin{abstract}
The in-situ grain structure and texture evolution during the whole process of friction stir welding (FSW) are clarified. As the base material approached the probe, grains were compressed, forming compression zone (CPZ). The grains evolved to fine equiaxed grains mainly through discontinue dynamic recrystallization (DDRX) and twining as it approached the tool. As material in MFZ rotated around the probe, the fraction of low-angle grain boundaries (LAGBs) was reduced, the ratio of twin boundaries increased, and the grain size distribution became wider, while the average grain size was fairly constant despite the increase in strain. After the material was deposited behind the probe, the grains began to grow. Deformation caused by tool shoulder disrupted the twin boundaries and generated some segments of LAGBs. In the post-weld zone, some LAGBs disappeared and new twin boundaries developed as a result of elevated temperatures. The B component $\{112\}<110>$ was developed and was sustained in the MFZ with its shear direction being consisted with the local probe rotation. The shear plan of B component maintained approximately $30 \mathrm{deg}$ away from the probe profile. In the weld zone behind the probe, the B component was weakened and evolved to a $\mathrm{C}$ component $\{001\}<110>$.
\end{abstract}

Keywords: texture; recrystallization; in-situ; friction stir welding; friction stir processing; electron backscattering diffraction (EBSD)

F.C. Liu, E-mail: fchliu@alum.imr.ac.cn, Tel: +1 801-422-5189, Fax: +1 801-422-0516. T.W. Nelson, E-mail: nelsontw@byu.edu, Tel: +1 801-422-6233, Fax: +1 801-422-0516. 


\section{Introduction}

Friction stir welding (FSW) which enables solid-state joining has become increasingly important in modern manufacturing. It has been considered to be one of the most significant development in welding techniques that has emerged in the past several decades. A fundamental understanding of microstructural evolution during FSW is of great interest for both academic research and industrial applications as the materials undergo large strain and high strain-rate plastic deformation at elevated temperatures during FSW [1-4]. The material recrystallization and texture evolution under such extreme deformation conditions is far from fully understand. Such knowledge is needed for understanding of the nature of materials and achieving precise control of the post-weld microstructure and properties.

Since the in-situ microstructural evolution during FSW cannot be observed directly, the microstructural evolution was traditionally estimated by a comparison of the microstructure in the parent material and in the weld zone [5-7]. However, due to the complexity of FSW process, the estimation of the FSW structure evolution through cross-sectional examination of the weld is inaccurate.

An early study for FSW of Al alloy showed that the weld zone just behind the probe consisted of extremely fine recrystallized grains [8]. The recrystallized grains grew under subsequent heating. Additional dislocations were introduced due to the forge effect of the tool shoulder [8]. Another study in FSW of 304L stainless steel showed that after the probe has passed, static recrystallization occurred in the weld zone containing high dislocation density [9]. These studies demonstrated that the grain structure produced by probe rotation has changed significantly under the action of tool shoulder and high-temperature exposure. 
In order to reveal more details of the grain structure evolution around the probe, some experiments have attempted to 'freeze' the FSW process through sudden stopping the tool and immediately quenching the work piece ('stop action' technique) [4,10-12]. Sectioning through the 'frozen' keyhole with the tool in place allowed the fine-grained material around the probe to be directly observed. It was shown that during FSW of $2195 \mathrm{Al}$, the grain refinement was driven by grain subdivision and thermally activated local boundary migration [10]. Strong $B / \bar{B}$ shear component, with the shear direction aligned approximately with the flow lines in the weld zone, was present throughout the weld $[10,11]$.

The grain structure development of AZ31 Mg ahead of the probe was found to be a complex process involving several stages $[4,12]$. An extensive $\{10 \overline{1} 2\}$ twining developed at the deformation zone far ahead of the probe. As the weld material approached to the probe, the twin boundaries deviated from the exact twin-matrix relationship and developed into general highangle grain boundaries (HAGBs). Simultaneously, low-angle grain boundaries (LAGBs) developed within the grain interiors. As the materials further approached to the probe, the grains and twins were geometrically oriented parallel to the probe surface. Necklace structure consisting of fine equiaxed grains developed along the original grain boundaries. At the region very near to the probe, the grain structure evolution was governed by continuous recrystallization and texture-induced grain convergence.

The investigations above have provided meaningful insights on the microstructure evolution around the FSW keyhole, which significantly enhanced the understanding of the material recrystallization and FSW process. However, all keyhole studies failed to recognize that the material distribution around the keyhole has been disturbed by the probe during weld 
termination. Thus, the microstructure evolution during steady state FSW was not properly represented.

Our recent study [13] showed that contact forces between the probe and the workpiece material cause the probe to deflect away from its "home" position during FSW. Once weld termination is activated, system relaxation allowed the probe to return to its "home" position along an arc route prior to tool extraction, disturbing the material distribution surrounding the keyhole. Such a material disturbing cannot be completely avoided. Even the tool rotation is stopped within 0.1 seconds after activating the emergency stop, a shift of probe in the keyhole is evident [10].

In our recent study [13], the probe route during weld termination was tracked and used to determine the probe position just prior to weld termination. With this approach, the in-situ material flow pattern around the probe has been presented [13]. However, the in-situ microstructure evolution is still unclear. This study aims to clarify the details of grain structure and texture evolution during the whole process of FSW, i.e. from material approaching the probe to material rotating around the probe and until material was deposited in the weld zone.

\section{Experimental}

A Convex-Scrolled-Shoulder-Step-Spiral (CS4) tools made of Polycrystalline Cubic Boron Nitride (PCBN) was used to weld hot rolled commercial 304L austenitic stainless steels at a tool rotation rate of $250 \mathrm{rpm}$, a welding speed of $100 \mathrm{~mm} / \mathrm{min}$, and a downward force of about $8 \mathrm{kN}$. The schematic diagram of the FSW tool is shown in Fig. 1a. A liquid cooled tool holder equipped with thermal couple telemetry system was used. An argon shielding system was applied to minimize oxidation of the workpiece surface. At the end of welding, an emergency stop was used, i.e., terminating the workpiece travel and tool rotation as fast as the machine is 
capable while maintaining welding force to reduce the system relaxation. Coolant was poured around the keyhole after weld termination in order to prevent significant grain growth. The keyhole was cooled to less than $200^{\circ} \mathrm{C}$ within $10 \mathrm{~s}$.

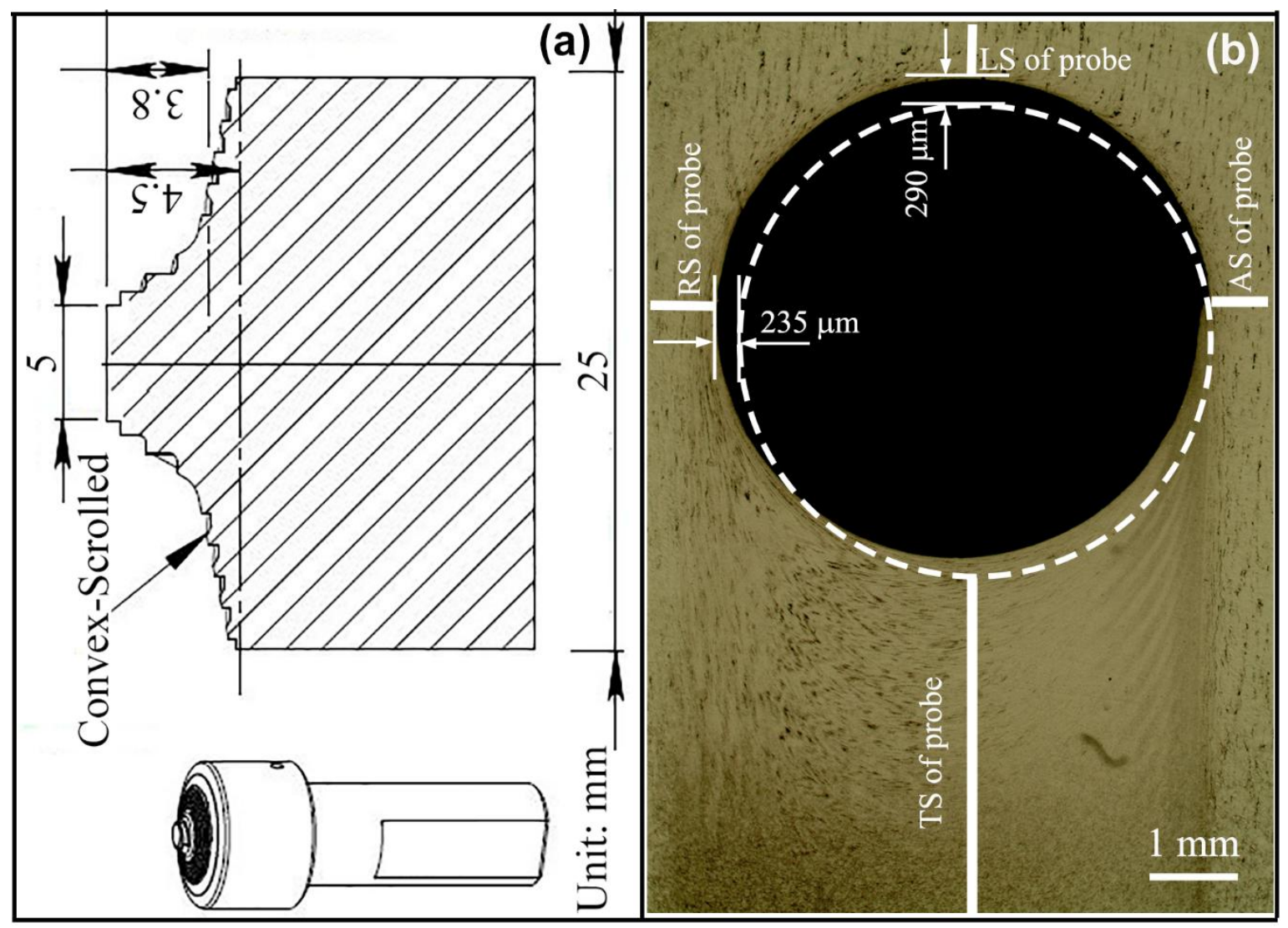

Fig. 1. (a) The schematic diagram of the tool geometry and (b) EBSD examination regions (white lines) at the advancing side (AS), leading side (LS), retreating side (RS) and tailing side (TS) of probe (probe position at the time of activation weld termination was marked using a dash circle).

The keyholes were removed and then sectioned using electrical discharge machining parallel to the welding surface for electron backscatter diffraction (EBSD) examination. The EBSD examination surfaces were marked in Fig. 1b. The EBSD sample was vibratory polished using $0.05 \mu \mathrm{m}$ colloidal silica after a standard mechanical polishing. High resolution EBSD data 
were obtained at $20 \mathrm{kV}$ at steps of $0.2 \mu \mathrm{m}$ using FEI Helios Nanolab 600 with a TSL channel EBSD system. The average confidential index (CI) for each EBSD map is higher than 0.5. In order to eliminate spurious boundaries caused by orientation noise, boundaries with misorientation less than $2^{\circ}$ were not considered.

\section{Results and analysis}

\section{1 microstructure of base material}

Fig. 2a shows the EBSD map of the as-received 304L stainless steel. The grains were colored according to their crystallography orientation relative to the normal direction of the welding plate. A color code triangle was overlapped on the grain map for reference. All the EBSD maps in this study were colored according to the same principle. The as-received 304L stainless steel consisted of annealed grains with an average grain size of about $25 \mu \mathrm{m}$. The fraction of LAGBs and twin boundaries were about $5 \%$ and $46 \%$, respectively. Fig. $2 \mathrm{~b}$ shows that the as-received 304L stainless steel exhibited some characters of the cube texture. A stronger cube texture was detected in $304 \mathrm{~L}$ stainless steel produced through rolling at $800^{\circ} \mathrm{C}$ with $90 \%$ reduction following a final annealing at $1000^{\circ} \mathrm{C}$ for $1 \quad \mathrm{~h}$ [14]. 


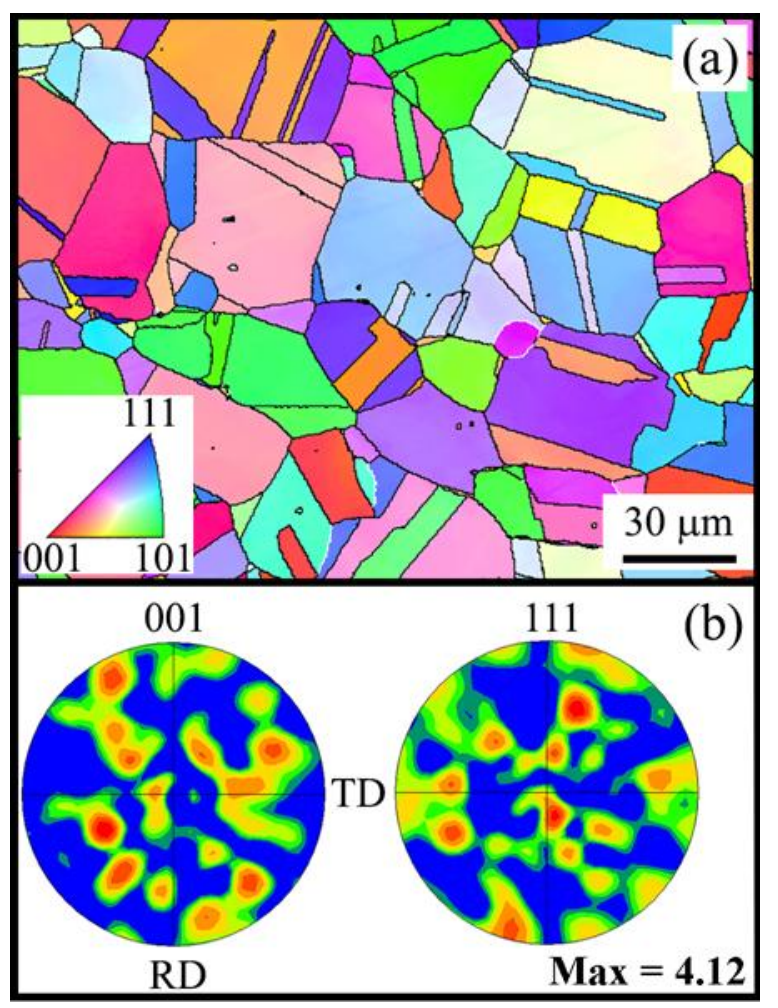

Fig. 2. Microstructure of as-received stainless steel: (a) EBSD map and (b) pole figures (RD: rolling direction; TD: traverse direction).

\subsection{In-situ microstructure statistics around probe.}

Quantitative microstructure details at the advancing side (AS), leading side (LS) and retreating side $(\mathrm{RS})$ of the probe were characterized and summarized in Fig. 3. Fig. 3a shows that the grain size decreased as the material approached the probe, demonstrating the grains of the asreceived steel were refined through recrystallization. Figs. $3 \mathrm{~b}$ and $\mathrm{c}$ show that the locations of the highest percentage of LAGBs coincided with the locations of the lowest ratio of twin boundaries. The highest percentage of LAGBs appeared at approximately 200, 450, and $620 \mu \mathrm{m}$ away from the probe at the AS, LS, and RS of the probe, respectively. In order to understand the microstructure evolution, more detailed microstructure examinations were performed on particular locations, which were marked on Fig. 3c. 

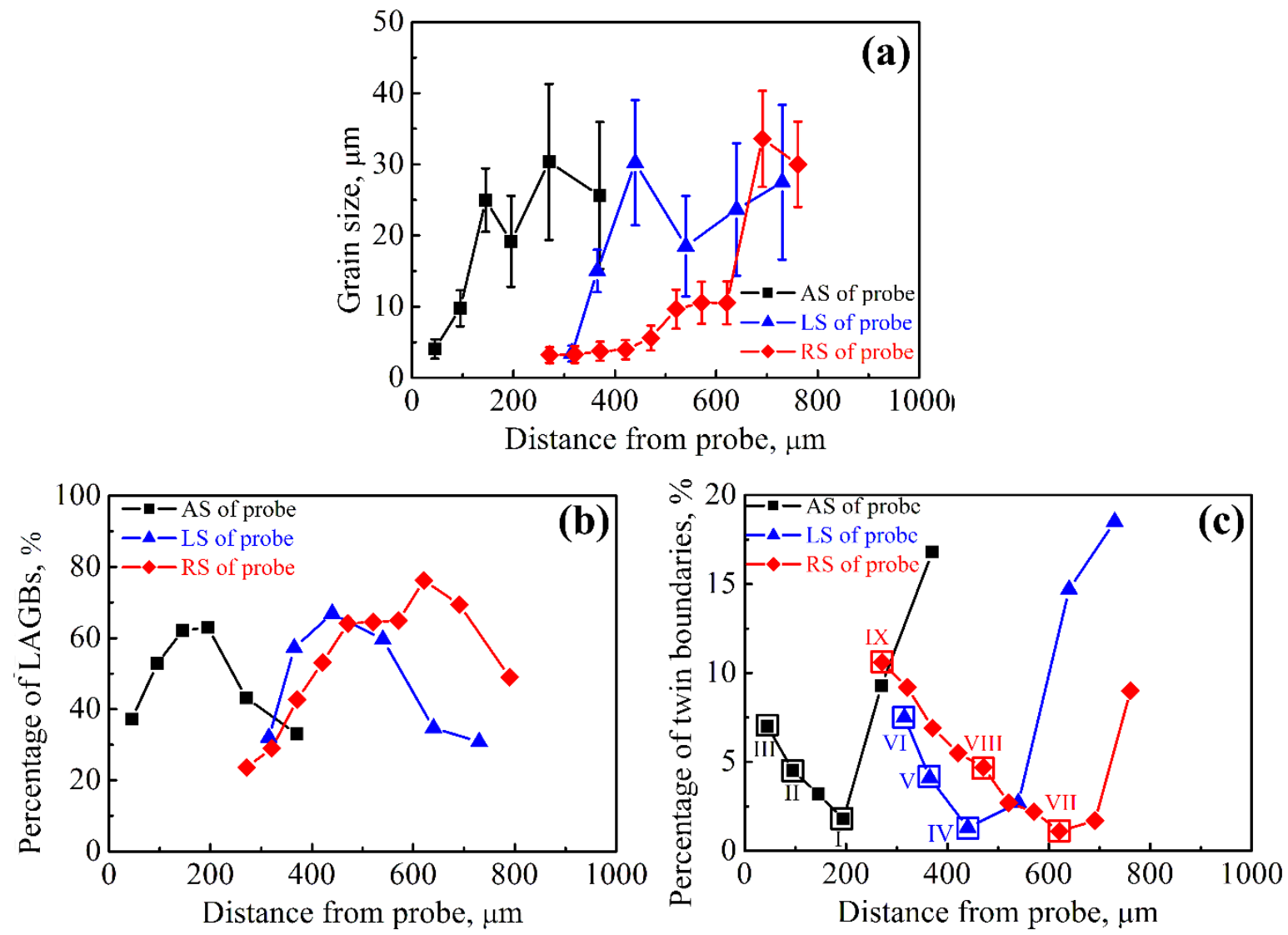

Fig. 3. Quantitative microstructure details at the AS, LS and RS of the probe: (a) grain size, (b) percentage of LAGBs and (c) percentage of twin boundaries.

\section{3 microstructure at AS of probe.}

Grain structure at the AS of the probe was detailed in Fig. 4. Fig. 4b shows that region I consisted of primarily coarse deformed grains and a few fine recrystallized grains. LAGB segments have developed in almost all the coarse grains. Most of the LAGB segments were short, curved and disconnected, indicating region I experienced a low degree of plastic deformation and did not accumulated sufficient energy for extensive recrystallization. Thus, region I contains high percentage of LAGBs (Fig. 3b).

Fig. 4e shows that almost all the twin boundaries in region I were deformed in to zigzag lines. The plastic deformation made the twin boundaries inherited from base material deviate 
away from the exact twin/matrix relationship (Fig. 4e). Such a phenomenon has been reported and explained as strain-induced crystallographic rotation of the twins and matrix from their original orientations [15]. As most of the original twin boundaries in region I have been disrupted and no new twins generated, a low fraction of twin boundaries was detected in region I (Fig. 3c).

Figs. $4 \mathrm{c}$ and $\mathrm{f}$ show an increase in LAGBs and twin boundaries in region II. This can be ascribe to the increased deformation. Some of the LAGB segments in region II have connected to each other and evolved into long HAGBs, subdividing the original coarse grains (Fig. 4c). Additionally, high volume of fine recrystallized grains have developed (Fig. 4c). These fine grains mainly developed through bulge nucleation, as indicated by arrows in Fig. 4c. This microstructure characteristic fits the definition of discontinuous dynamic recrystallization (DDRX) controlled by boundary migration. Although region II contained higher density of LAGBs than region I (Figs. $4 b$ and c), the ratio of LAGBs decreased in region II (Fig. 3b), indicating the HAGBs growth faster than the LAGBs. 


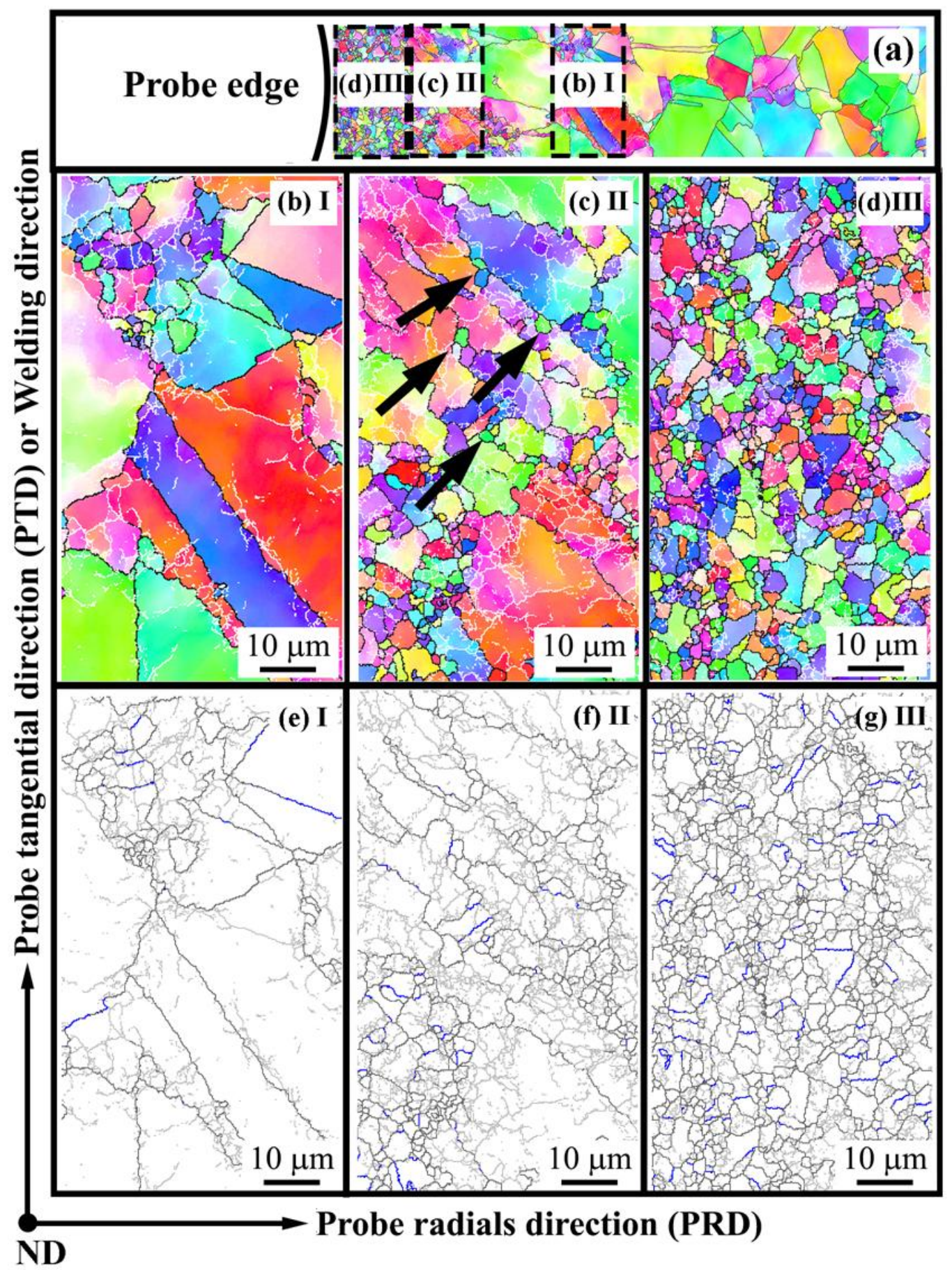

Fig. 4. Grain structure at AS: (a) examination zone; grain structure in (b) region I, (c) region II and (d) region III; twin boundary distribution in (e) region I, (f) region II and (g) region III. (HAGBs were marked as black lines in (a)-(d) and dark grey lines in (e)-(g). LAGBs were marked as white lines in (a)-(d) and greyish lines in (e)-(g). $\Sigma 3$ boundaries are marked as skyblue lines in $(\mathrm{e})-(\mathrm{g}))$. 
The longer HAGBs in region II were mostly aligned at an angle of $25-40$ o to the probe tangential direction (PTD). Similarly, in a sample deformed under rolling, the long boundaries of deformation bands are aligned at an angle of $25-40 \mathrm{deg}$ to the rolling direction [16]. The distribution of the long HAGBs in region II demonstrated that the materials primarily experienced a compression deformation and the compression direction was normal to the probe tangent.

Fig. 4d shows that region III consisted of a bimodal distributed grain structure: fine grains with a grain size less than $2 \mu \mathrm{m}$ and medium-sized grains whose size was about 5-10 $\mu \mathrm{m}$. The fine grains mainly appeared as necklace or clustered islands along the HAGBs of the medium-sized grains, indicating the fine grains were developed through DDRX. LAGB segments were observed within most of the grains, indicating these grains experienced additional plastic deformation following recrystallization. The evolution of LAGBs-to-HAGBs was detected only in some of the medium-sized grains. A higher volume of new twins generated in region III compared to region II (Figs. 4f and $4 \mathrm{~g}$ ). The twin boundaries refined the grains and provided additional nucleation sites for DDRX during their initial present and migration. Thus, grain structure evolution in region III appears to be a competition among DDRX, continuous dynamic recrystallization (CDRX) and twin dynamic recrystallization (TDRX). DDRX is the dominant mechanism for the grain structure refinement.

\section{4 microstructural ahead of probe}

Fig. 5a shows the grain structure at the LS of probe. The material in region IV maintained coarse grain structure, and only developed a few of LAGB segments, evidence of low plastic deformation (Fig. 5b). Fig. 5c shows that the transition zone between the coarse grain zone and the fine grain zone is extremely narrow: only about $30 \mu \mathrm{m}$. This indicates that the coarse grains 
recrystallized rapidly when they collided with the hot fine grains in material flow zone (MFZ) [13]. Previous investigations showed that the LS has the steepest temperature gradient compared to other regions around the probe $[17,18]$. The steep temperature gradient at LS caused the thinning of the transition zone. Most of the fine recrystallized grains in region $\mathrm{V}$ have high misorientation relative to their parent grains according to the crystallography map (Fig. 5c). Thus, the grain refinement in region $\mathrm{V}$ should be achieved mainly through DDRX, as CDRX through sub-grain rotations always lead to a gradual misorientation conversion. Fig. 5d shows that the material in region $\mathrm{V}$ consisted of fully recrystallized fine grains with grain size less than $5 \mu \mathrm{m}$. New twins which contributed to the grain refinement in MFZ were observed in region VI (Fig. $5 e)$.

Lower stacking fault energy of 304 stainless steel makes the dislocations less mobile and lesser number of them can be accumulated to form LAGBs. Therefore, DDRX stead of CDRX is the favorite recrystallization mechanism at elevated temperatures. Due to the low mobility of dislocations in 304 stainless steel, the low deformation energy stored in stainless steel is hard to be totally released through dislocation movements. If the deformed energy is not sufficient to induce DDRX, twin boundaries are motived to form preferentially to release the energy. 


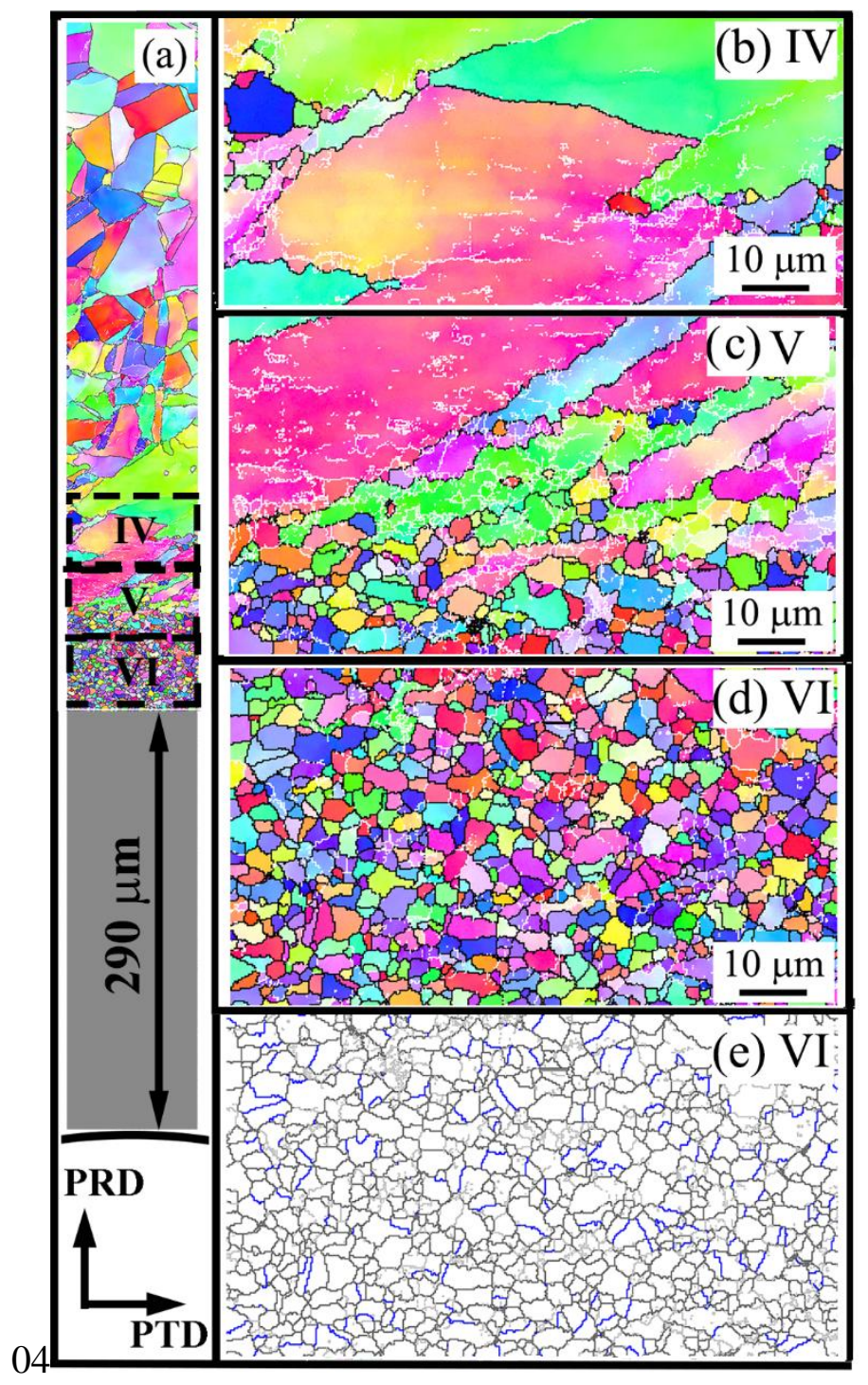

Fig. 5. Grain structure at LS: (a) examination zone; grain structure in (b) region IV, (c) region V and (d) region VI; (e) twin boundaries in region VI.

\section{5 microstructure at RS of probe}

Three typical locations at the RS of probe were examined in detail (Fig. 6a). The coarse grains in region VII were compressed and align roughly along the probe rotation direction (Fig. 6b). The coarse grains at RS, compared to that at the LS and AS, experienced more plastic deformation and contained higher volume of LAGB segments. Due to the low stacking fault energy of 304L stainless steel, the rearrangement of LAGB segments encounter high resistance. 
Most of the LAGB segments in region VII did not developed into regular grain boundaries. DDRX was also limited in region VII, indicating the deformation temperature is low and insufficient for extensive DDRX.

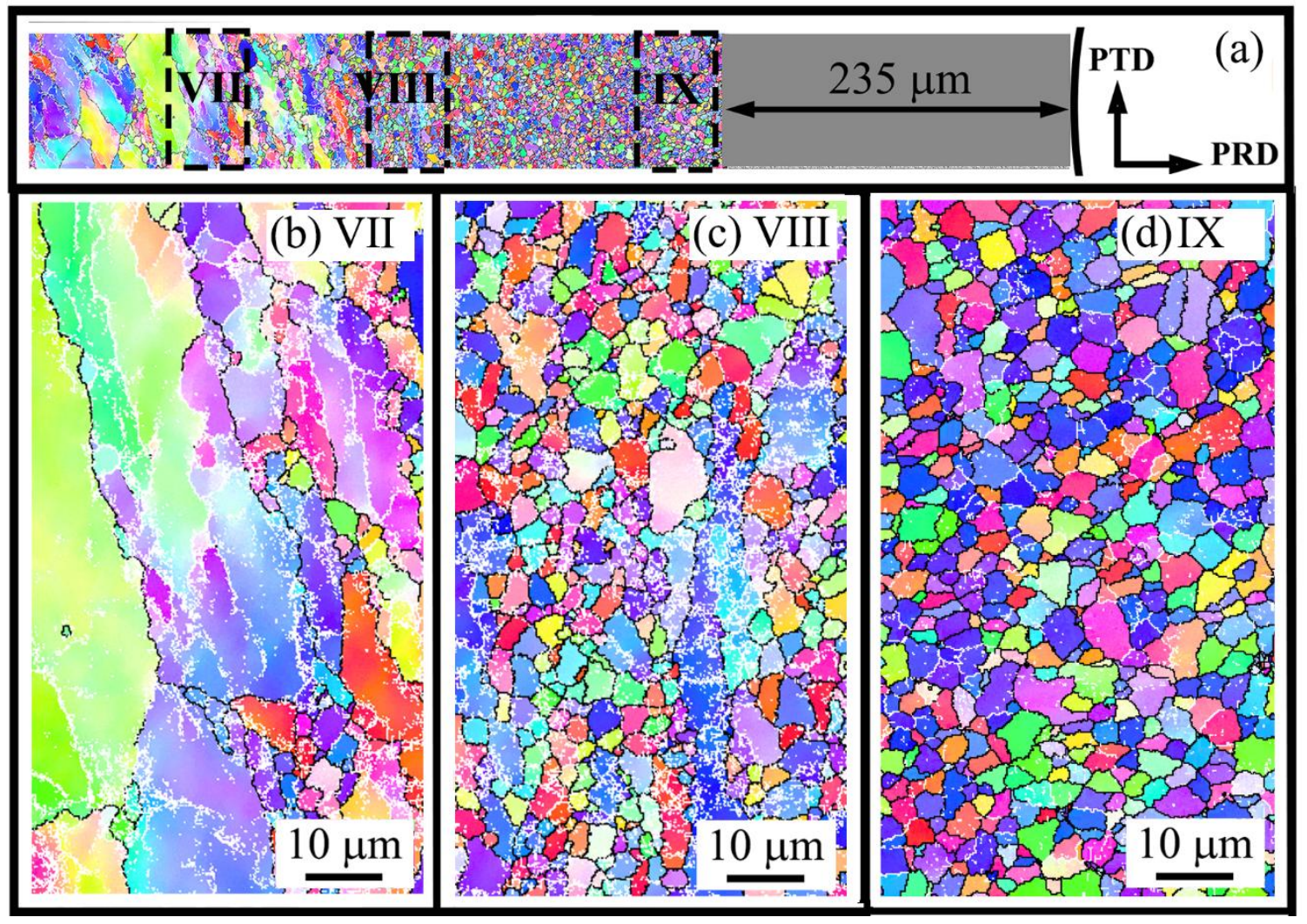

Fig. 6. Grain structure at RS: (a) examination zone; grain structure in (b) region VII, (c) region VIII and (d) region IX.

DDRX become more pronounced in region VIII. The rearrangement of LAGB segments into HAGBs confronted high resistance in this region. Only a small number of grain boundaries developed through geometric dynamic recrystallization. Compared with other fine grain zones, region VIII contain more LAGB segments. This is because the material in region VIII rotated around the outer most region of the MFZ during FSW [13]; likely deformed at the lowest temperature and strain rate compared to other region of the MFZ. 
The material in region IX came from the LS of the probe and has rotated around the probe about one quarter turn. Regions IX at RS (Fig. 6) and region VI at LS (Fig. 5) have similar grain structure and grain size, demonstrating that the grains were not significant refined after the material entered the MFZ despite the increase of strain.
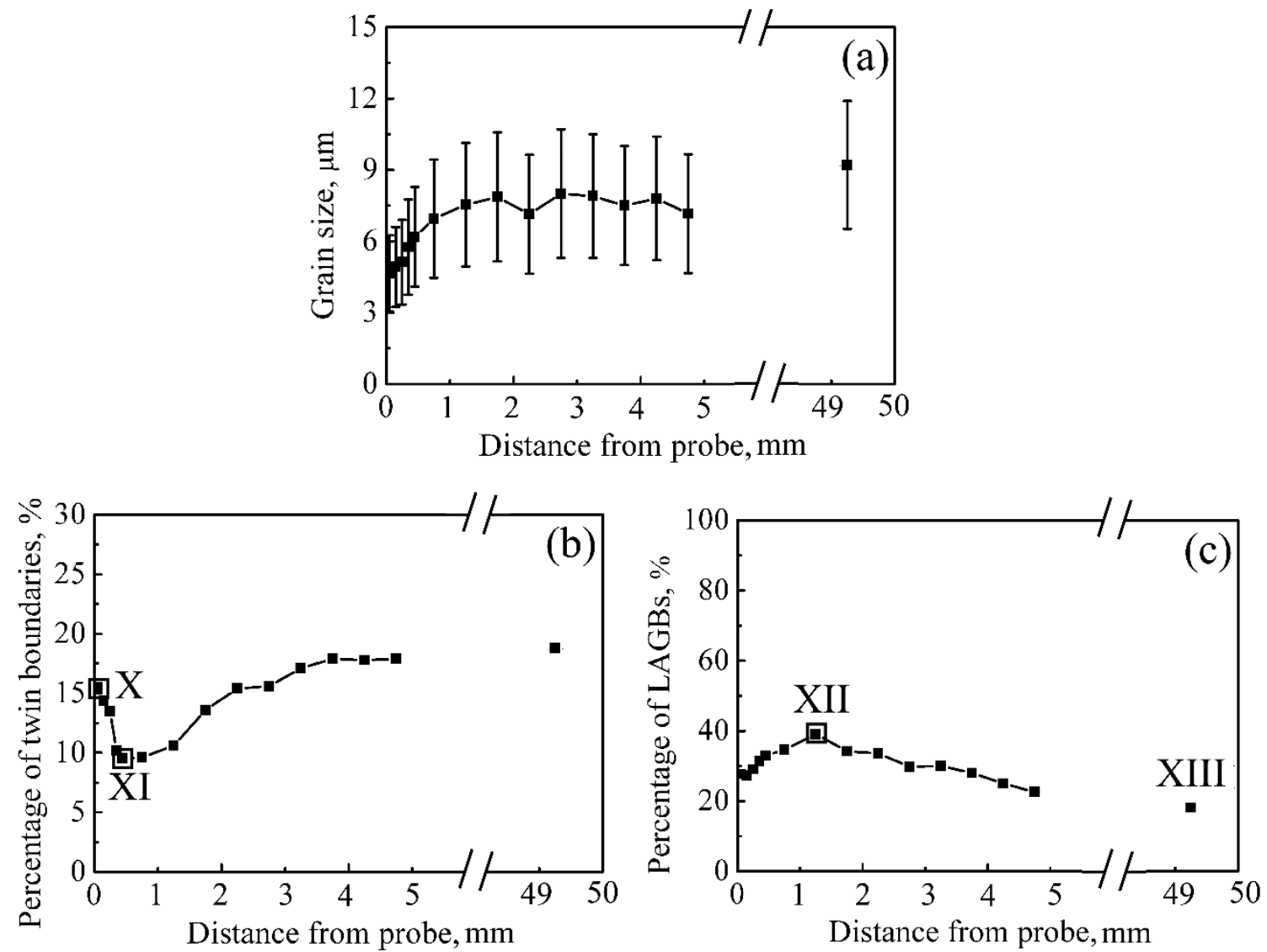

Fig. 7. Quantitative microstructure details on the TS of probe: (a) grain size, (b) percentage of twin boundaries and (c) percentage of LAGBs.

\section{6 microstructure at TS of probe}

Quantitative microstructure details at the trailing side (TS) of probe was summarized in

Fig. 7. The grain size increased rapidly after deposition behind the probe (Fig. 7a) and then the growth slow significantly beyond $1 \mathrm{~mm}$. The lowest percentage of twin boundaries and the highest ratio of LAGBs appeared at approximately 0.4 and $1.2 \mathrm{~mm}$ behind the probe, respectively. In order to understand the microstructure evolution, further microstructure analysis 
were performed at four typical locations (Figs. $7 \mathrm{~b}$ and c): (1) region $\mathrm{X}$ which preserved the major microstructure characterization of MFZ behind the probe; (2) region XI which contained the lowest fraction of twin boundaries; (3) region XII which had the highest ratio of HAGBs; and (4) region XIII, in which the plastic deformation terminated.

Fig. 8a shows that region $\mathrm{X}$ consisted of fine recrystallized grains. Compared with other MFZs (Figs. 5d and 6d), region $\mathrm{X}$ contained more annealing twins. Fig $8 \mathrm{~b}$ shows that some grains in region XI coarsened significantly. Most of the old twin boundaries have migrated into ordinary HAGBs during grain coarsening, leading to a low fraction of twin boundaries in region X (Fig. 7b). Fig. 8c shows that almost all the coarse grains in region XII contained LAGB segments, indicating these grains experienced plastic deformation during their coarsening. The plastic deformation has terminated at region XIII, as the shoulder has passed. The density of LAGB segments were significantly reduced and a few of new twin boundaries developed as a result of high temperatures (Fig. 8d). 


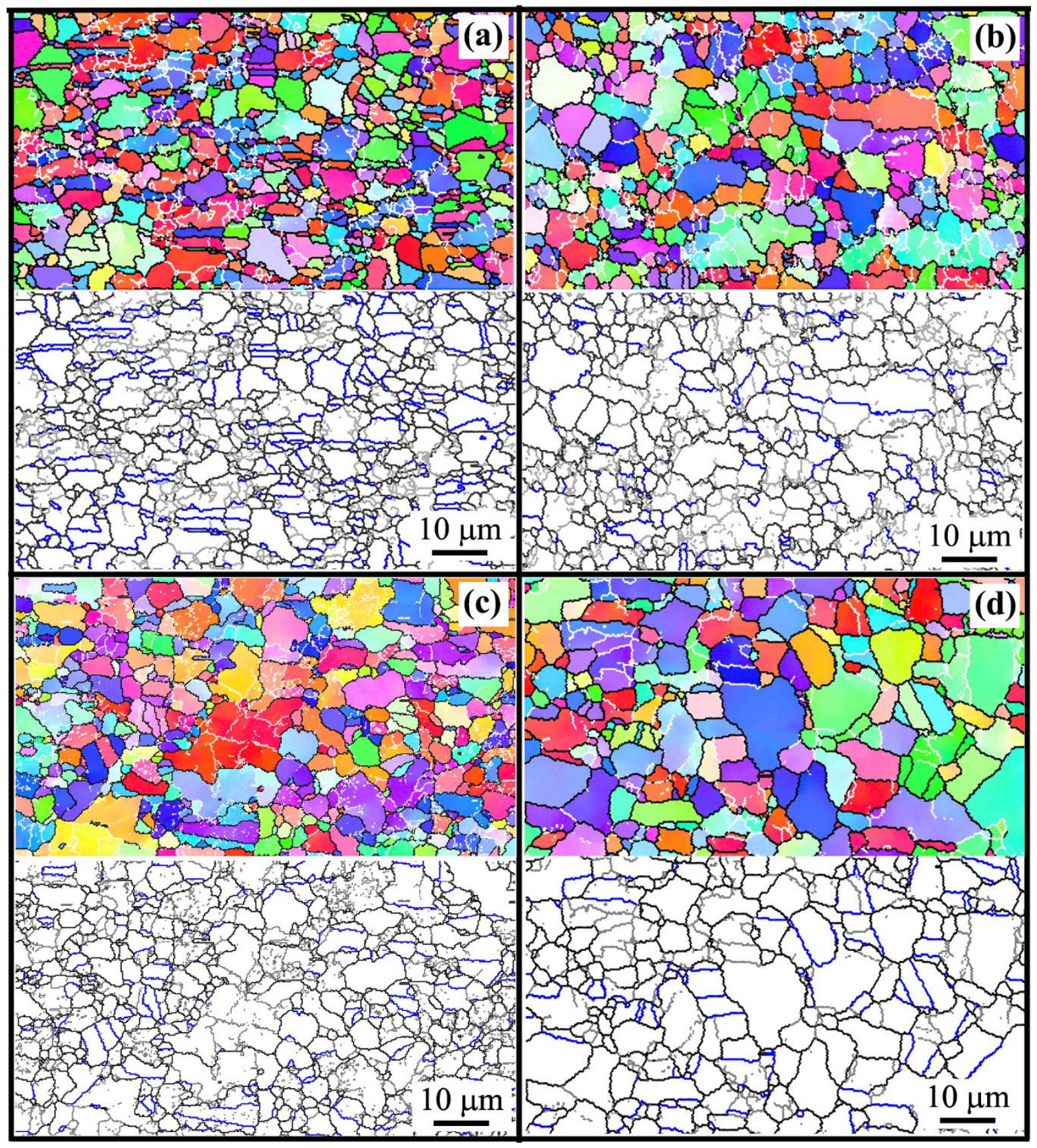

Fig. 8. EBSD maps obtained at (a) region IX, (b) region X, (c) region XI, and (d) region XII ( $\Sigma 3$ boundaries are depict as sky-blue lines). 


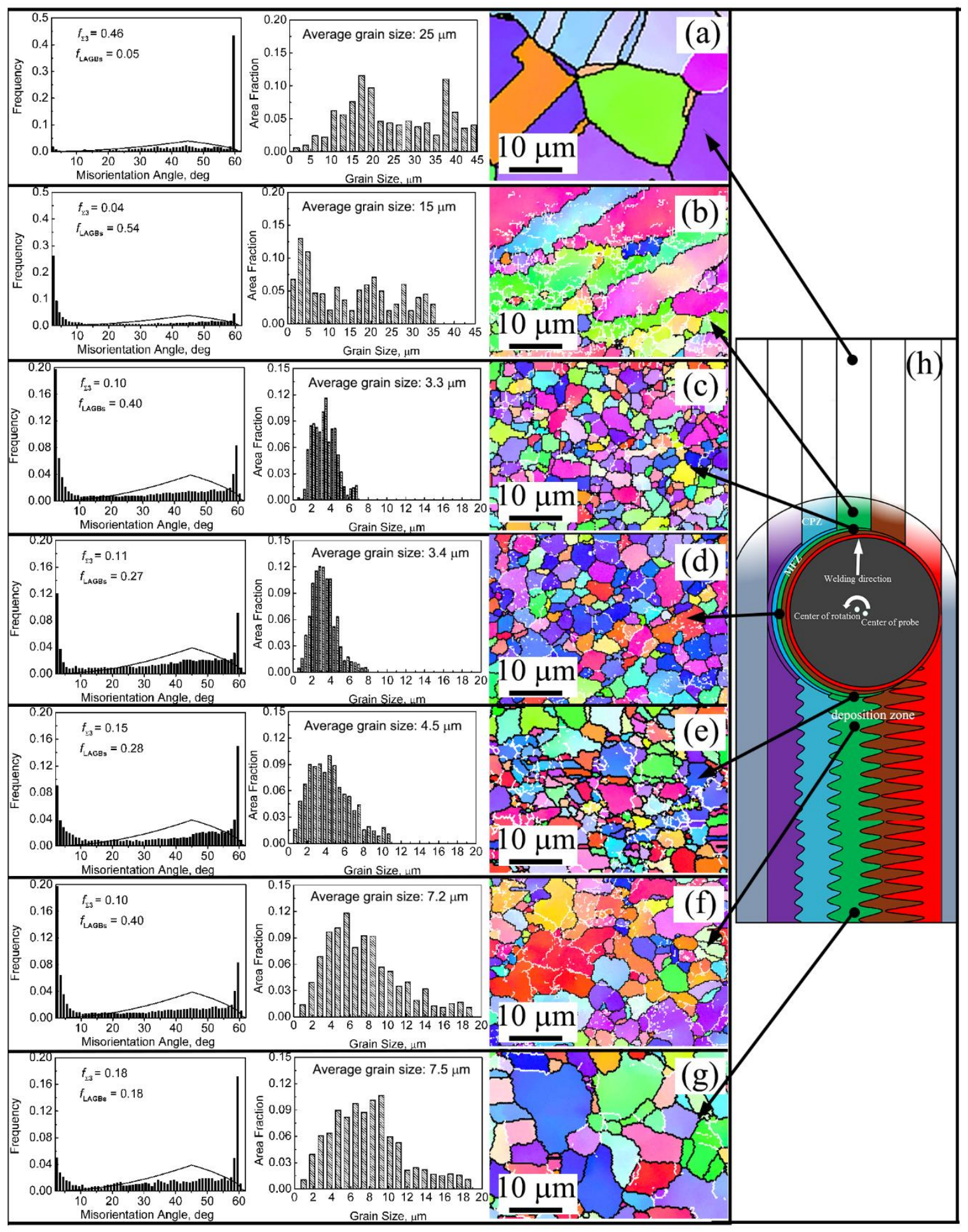

Fig. 9. Grain structure evolution during FSW: (a) BM, (b) CPZ, (c) MFZ at LS, (d) MFZ at RS, (e) MFZ at TS, (f) forge and torsion zone, (g) annealing zone and (h) Schematic of material flow.

\section{Discussion}




\subsection{Grains structure evolution during FSW}

During FSW, the material intersecting the path of probe deformed in a similar manner. As the probe approaches, the material is initially compressed, then rotates around the probe, and is finally deposited behind the probe at roughly the same transverse position as its beginning. The typical microstructure evolution of stainless steel during this deformation process can be present through a microstructure analysis along the center of the weld path.

The as-received stainless steel consisted of coarse annealed grains $(25 \mu \mathrm{m})$ and contained high fraction of annealing twins (46\%). The grain interiors were almost free of LAGBs (Fig. 9a). With the approaching of the probe, the microstructure of the as-received stainless steel evolved to a deformation structure, forming a CPZ. In the CPZ, high density of LAGB segments were generated (Fig. 9b). Some of the LAGB segments developed into long HAGBs, subdividing the former coarse grains, which is a process of geometric dynamic recrystallization. A volume of fine equiaxed grains developed through DDRX along the HAGBs and at heavily deformed locations. Most of the twin boundaries inherited from base material have deviated from the exact twin/matrix relationship (Fig. 4e) due to the plastic deformation. No new annealing twins were generated in the CPZ (Fig 11b), indicating the deformation temperature was still low. Thus, a high ratio of LAGBs (54\%) and a low fraction of twin boundaries (4\%) existed in CPZ.

As the CPZ collided with the hot MFZ, the deformed grains in the CPZ were heated further and experienced more plastic deformation, causing it to evolve into fine equiaxed grains mainly through DDRX. Twining also contributed to the grain refinement in MFZ (Fig. 11c). Thus, the MFZ contained high ratio of twin boundaries (Figs. 9c-e). Since the high-temperature flow resistance of the recrystallized grains was reduced due to grain refinement [19-22], the new 
recrystallized grains were added to the MFZ and driven to rotate around the probe. It is noted that the material has recrystallized at the beginning of its rotation around the probe (Fig. 9c).

Figs. 9c-e illustrate that as the material rotated in the MFZ, the fraction of LAGBs was reduced, the ratio of twin boundaries increased, and the grain size distribution became wider. All of these microstructure characteristic indicate that the deformation temperature increased as the material rotated around the probe. Previous simulation results also showed that the material just behind the probe had the highest temperature $[18,27]$. The average grain size in MFZ is fairly constant despite the increase in strain. This is an extreme case in that the rate of grain coarsening and recrystallization reaches an equilibrium. In this case, the grain size is governed by the deformation strain-rate and temperature rather than the strain [23, 24]. The combined effect of strain rate $(\dot{\varepsilon})$ and deformation temperature $(T)$ are often described by the Zener-Hollomon parameter $(Z)$, as defined [28] $Z=\dot{\varepsilon} \exp (Q / R T)$ where $R$ is the gash constant and $Q$ is the relative activation energy for deformation. The grain refinement can be achieved through increasing $\mathrm{Z}$ value (i.e. an increase in strain rate and/or a decrease in deformation temperature). For example, after additional cooling water was used to reduce the deformation temperature during FSW $[8,20,25,26]$, ultrafine grains were produced in the weld zone of aluminum alloys.

After the material was deposited behind the probe, it still experienced plastic deformation at elevated temperatures. Compared to the shear deformation around the probe, the deformation rate in the deposition zone behind the probe is lower. Grain coarsening began to control the process, leading to higher grain size and more dispersed grain distribution. The twin boundaries inherited from MFZ evolved to ordinary HAGBs through grain boundary migration. The plastic deformation caused by the tool shoulder generated some segments of LABGs within the coarse 
grains but was insufficient to induce recrystallization. Thus, a low fractions of twin boundaries and LAGBs were observed in the deposition zone just behind the probe (Fig. 9f).

After the tool shoulder has passed, the material is still exposed to elevated temperatures but the plastic deformation is negligible. Under this static annealing condition, the density of LAGBs decreased due to recovery. Previous in-situ TEM annealing experiments [29] showed that subgrains might rotated by boundary diffusion processes until adjacent subgrains were of similar orientation. The subgrains involved would then coalesce into one larger grain or subgrain with little boundary migration. The reduction of LAGBs in the weld zone (Fig. 9g) may be associated with the boundary diffusion. Besides recovery, new annealing twins developed. Compared to other HAGBs, twin boundaries are motived to form preferentially to release the low energy stored in the material (from the low plastic strain caused by tool shoulder). Thus, a low fraction of LAGBs and relative high fraction of twin boundaries were observed in the weld zone.

\subsection{Texture evolution during FSW}

During FSW, the deformation introduced by the rotating tool is predominately in the form of simple shear. The resultant texture are expected to comprise of ideal simple shear texture components. Texture identification can be completed by a direct comparison with ideal shear texture components that have been reported in literatures for the face centered cubic (f.c.c) [30,31]. Because various ideal shear texture components have been proposed in the literatures [32-34], it is instructive to summarize the pole figures here for easy comparison. In Fig. 10, the torsion axis is vertical, the shear direction (SD) of the lower sheared deformed material points to the right and the shear plane normal (SPN) points to the top. The sense of shear is negative, as for a left-handed screw axis. 


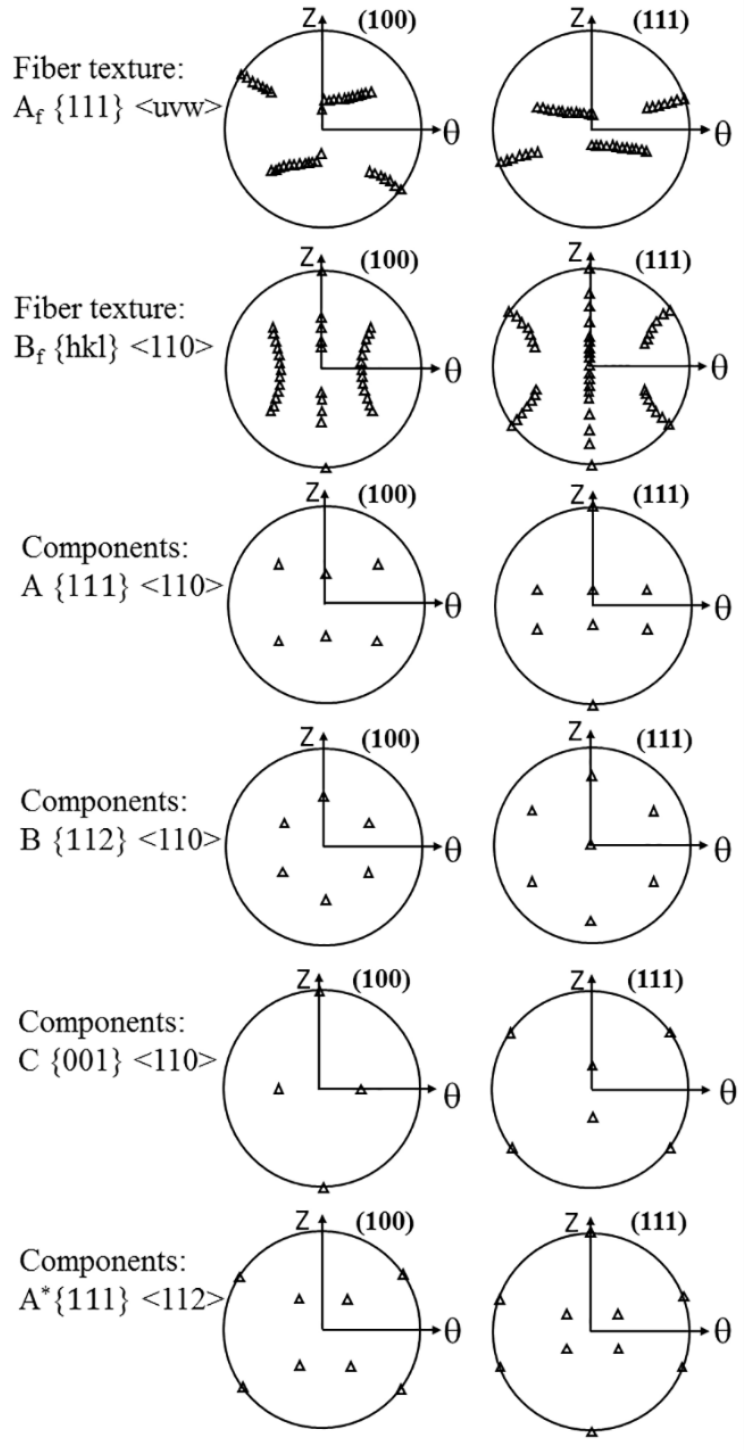

Fig. 10. Pole figures representation of idealized torsion fiber texture $A_{f}$ and $B_{f}$ as well as simple shear component A, B, C, and $\mathrm{A}^{*}$. ( $\theta$ is the shear direction and $\mathrm{z}$ is the shear plan normal direction).

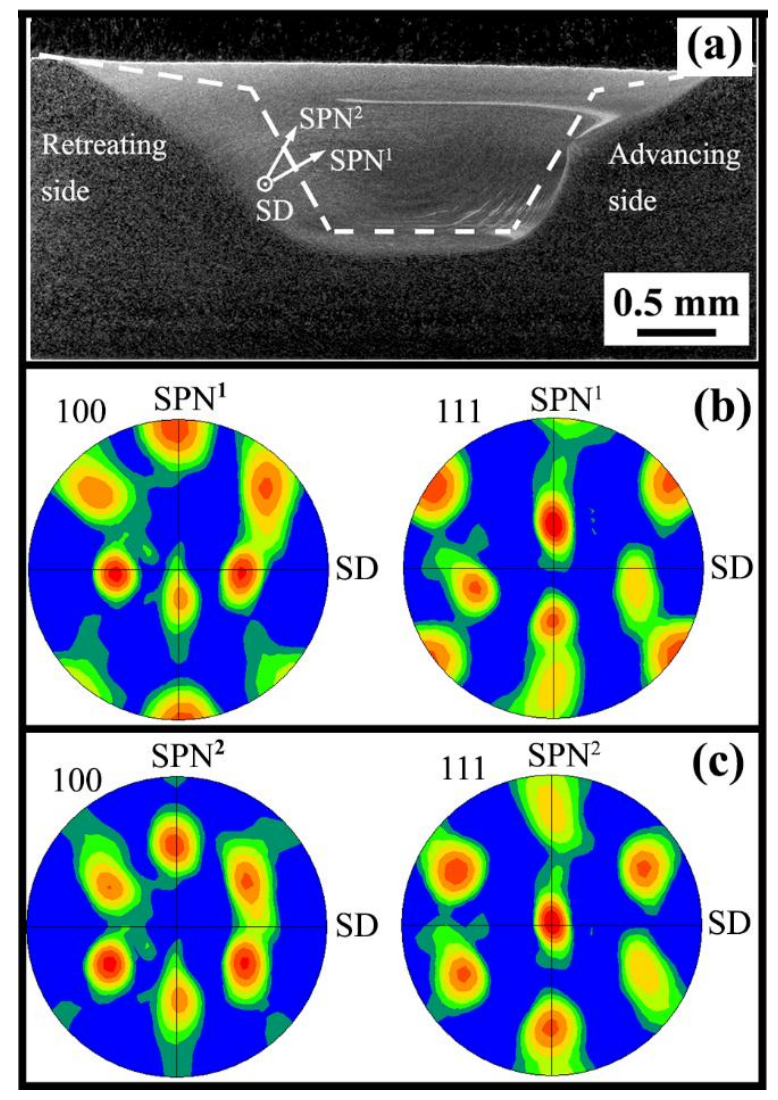

Fig. 11. (a) Cross section view of FSW stainless showing the orientation relationship between SPN and the outlines of probe and process zone; (b) pole figures from the EBSD data obtained at the RS of MFZ (region IX): (b) after rotating pole figures to the plan of SD and SPN1; (c) after rotating pole figures to the plan of SD and SPN2. 
The complex three-dimensional nature of the shear surfaces generate during FSW cause the orientation of the local shear coordinate system to vary as a function of position around the probe. Prior to do the identification, it is necessary to rotate the crystal reference frame to align with the local shear coordinate system. Fonda et al. [30] have introduced a methodology to align the texture analysis reference frame with the local shear coordination system at that location using geometry-based rotations. One of the important issues to mention here is that the relation between the texture reference frame and the sample coordinate system need to be determined prior to the rotations. This is because their relation may vary with the preset parameter or version of the EBSD analysis software.

The cross-section of the FSW stainless steel is shown in Fig. 11a. An outline of the welding tool was schematically marked using dash white lines. Due to the effect of tool shoulder, the shape of stir zone did not match with the probe outline. It is possible for the shear plane of deformation to be aligned with the probe profile, the processing profile, the tool shoulder surface or a plane among them. In order to determine the shear plane orientation, the pole figure reference frame need to be rotated to the assumed local shear coordinate system. When the shear plane is assumed to be parallel to the probe profile, the plane defined by SPN ${ }^{1}$ and SD in Fig 11a is treated as the texture analysis plane. Fig. $11 \mathrm{~b}$ shows the pole figures analyzed on the plane of $\mathrm{SPN}^{1}$ and SD. A rotated shear component $\mathrm{B}\{112\}<110>$ was observed but the SPN is about 30 deg away from the $\mathrm{SPN}^{1}$. When the texture analysis plane is placed on the plane defined by $\mathrm{SPN}^{2}$ and SD, all the peaks of the pole figures match well with the B component (Fig 11c). This demonstrates that (1) the texture in region IX is dominated by B component, (2) the shear plane of region IX is approximately parallel to the processing profile and (3) the SD is along with the 
probe rotation direction. Two factors may be responsible for the deviation of SPN away from probe profile. First, the material deformation in region IX is partly affected by the shoulder which tend to make shear plane align with its surface. Second, region IX is closer to the process profile than the probe profile (Fig. 6a).

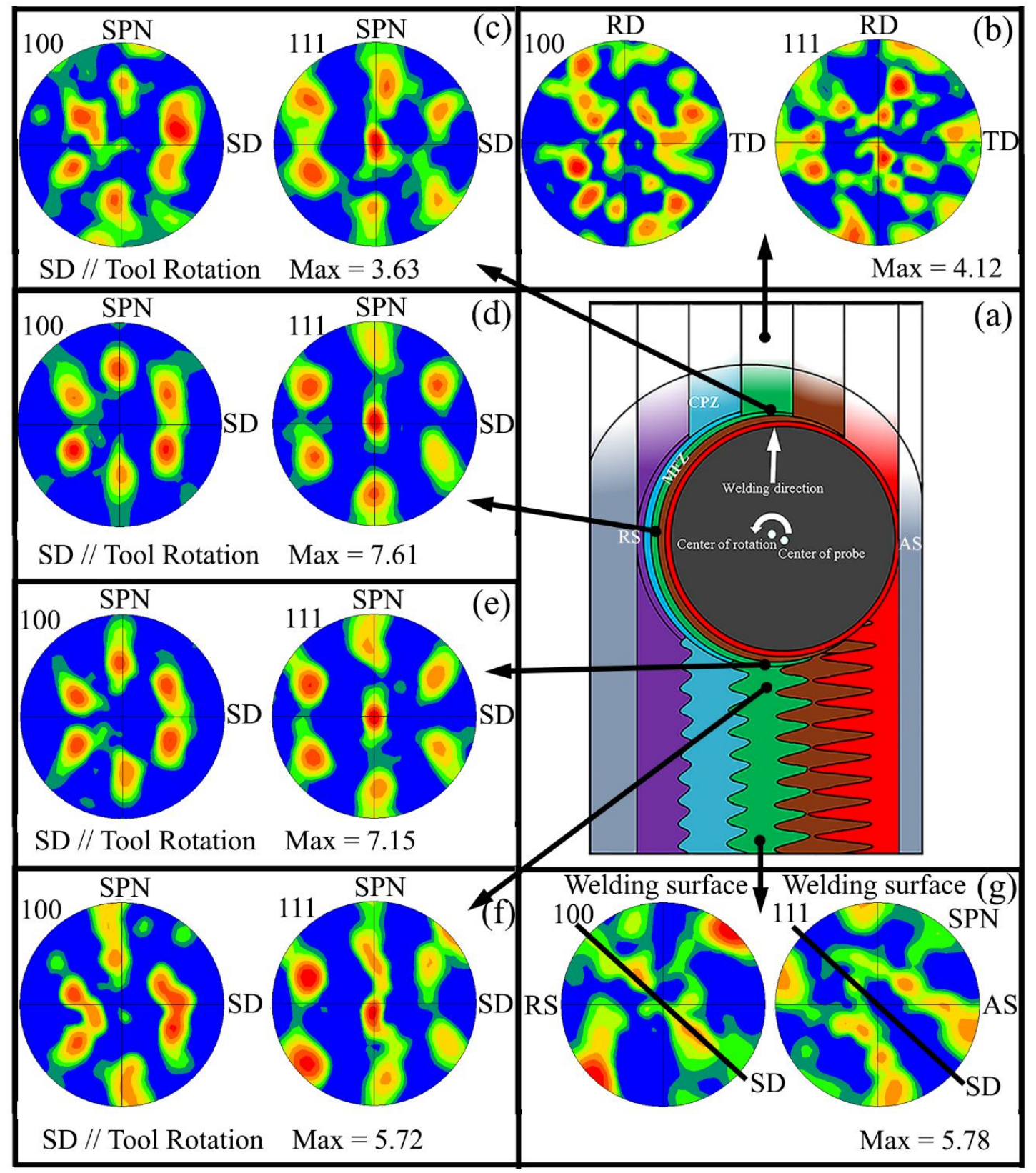

Fig. 12. Texture evolution during FSW: (a) Schematic of material flow, (b) BM, (c) MFZ at LS, (d) MFZ at RS, (e) MFZ at TS, (f) forge and torsion zone, and (g) annealing zone. 
After properly rotating the texture analysis reference frame to the local shear coordinate system, the local textures around the probe is summarized in Fig. 12. The as-received stainless steel had some characteristic cube texture (Fig. 12b). The B component developed in the MFZ and maintained in the MFZ with its shear direction being consisted with the local probe rotation (Figs. 12c-e) at that location. The shear plan of B component maintained approximately $30 \mathrm{deg}$ away from the probe profile at the LS, RS and TS of the probe. After material was deposited behind the probe, the B component was weakened (Figs. 12f). As the deformation in the deposition zone is mainly caused by shoulder rotation, the pole figure analysis plane in Fig. $12 \mathrm{~g}$ is placed to be along the cross section of the weld. The $\mathrm{B}$ component has evolved to $\mathrm{C}$ component $\{001\}<110>$ under the action of the shoulder rotation (Fig 12g). The SD of C component was not exactly parallel to the shoulder rotation but deviated approximately $40 \mathrm{deg}$ away from it, indicating that besides the rotation, the shoulder also introduced a deformation component in the direction normal to the welding surface. This is consistent with one of the main functions of the shoulder: to provide downward force during FSW.

The stainless steel which is a low stacking-fault energy (SFE) material has been deformed to a very high strain at high strain-rate and elevated temperatures. Thus, the texture trends so clearly displayed in FSW of stainless steel do not have a counterpart in previous results. A review of previous literature about torsion texture is helpful to understand the texture evolution during FSW. Torsion texture in metal of f.c.c crystal structure have been simulated by Canova et al. [32]. Their model predicted a unique $\mathrm{C}$ component at intermediate strains and room temperature. This prediction is in good agreement with some experimental room temperature pole figures $[33,34]$. The variation in torsion texture formation as a function of material has been investigated [35,36]. After materials were deformed to a strain of approximately 2 at room 
temperature, a combination of $\mathrm{C}$ component and $\mathrm{B}_{\mathrm{f}}$ fiber texture was present in the high $\mathrm{SFE}$ materials, $\mathrm{Ni}$ and $\mathrm{Cu}$ while the $\mathrm{B}$ component dominated the texture in the low SFE materials, $\mathrm{Cu}$ $30 \mathrm{Zn}$ and $\mathrm{Ni}-60 \mathrm{C}_{\mathrm{O}}$. The $\mathrm{B}$ component can also be produced in $\mathrm{Cu}-3 \mathrm{Zn}$ at large strains or very low deformation temperature of 77K [37]. It is interesting that Montheillet et al. [33,34] showed that as the strain increased to very high strain of 31 , the $\mathrm{C}$ component was replaced by $\mathrm{B}$ component in pure aluminum at the temperature of $400^{\circ} \mathrm{C}$. Fonda also observed the B component in the post-weld zone of FSW aluminum alloy [31]. These investigations indicate that the B component can be easily produced in low SFE materials at room temperature and low strain. In the high SFE materials, the B component can be generated at very high strains or very low temperatures.

The present study showed that the B component developed and maintained in the MFZ evolved to the $\mathrm{C}$ component after material was deposited behind the probe. The main difference in deformation between the MFZ and deposition zone is the deformation strain rate $(\dot{\varepsilon})$. The materials in MFZ deformed at high strain rates and elevated temperatures, its $\mathrm{Z}$ value (ZenerHollomon parameter) does not change significantly compared to quasi-static deformation at room temperature. Thus, the B compound, which is considered to be the dominant component of the texture observed at low temperatures in low SFE materials, was detected in the MFZ. The Z value in the deposition zone is estimated be much lower than that in the MFZ and that obtained at room temperature deformation. The development of $\mathrm{C}$ component in deposition zone is believed to be associated with the low $\mathrm{Z}$ value.

\subsection{Microstructure evolution adjacent to weld zone}

In this study, the definition of thermal mechanical affected zone (TMAZ) is the region along both sides of the stir zone which was not driven to rotate around the probe but experienced 
plastic deformation during welding. According to the nature of material flow, regions III (Fig. 4b) was recognized as the TMAZ adjacent to MFZ at AS and was defined as AS-TMAZ, while region VI (Fig. 6b) is the TMAZ adjacent to MFZ at RS, and was defined as RS-TMAZ. Fig. 13 shows that the AS-TMAZ and RS-TMAZ have significantly different misorientation distribution. This is because these two regions have different deformation history.
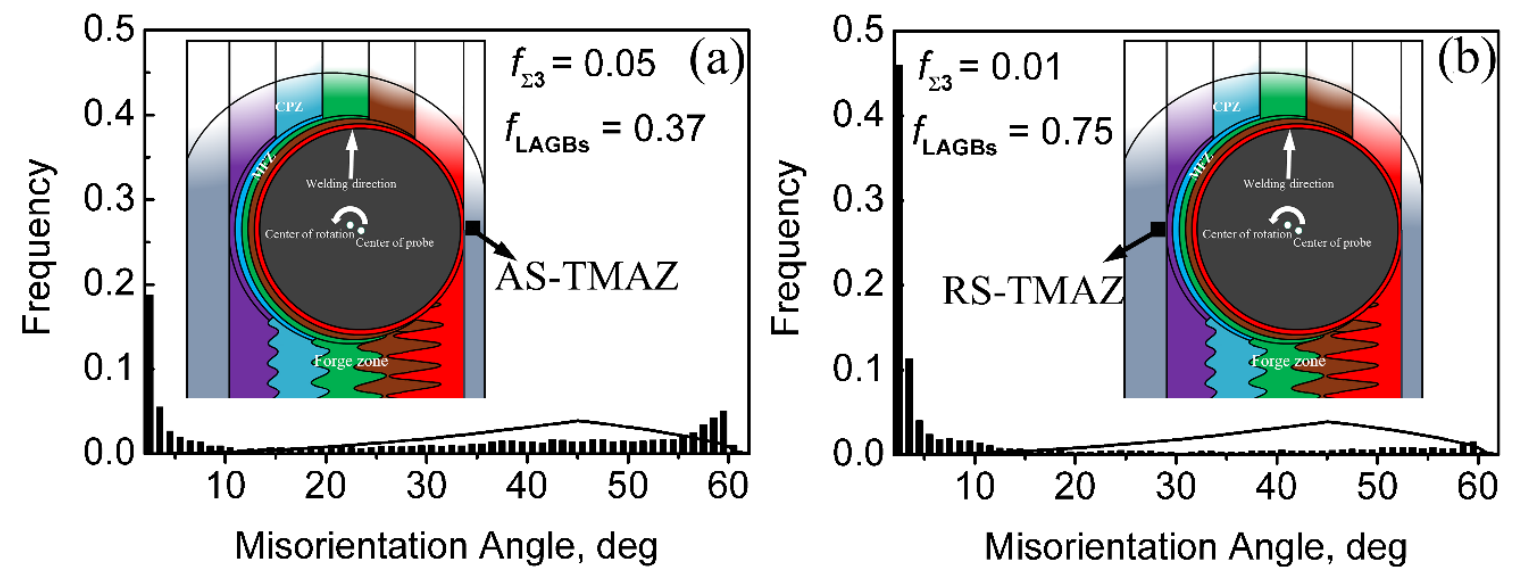

Fig. 13. Misorientation distribution at (a) AS-TMAZ and (b) RS-TMAZ.

With the approach of the probe, a thin layer of material at AS adjacent to the probe was refined through recrystallization. This thin layer of material was rotated by the probe as its hightemperature flow resistance was reduced due to grain refinement [19-22]. Simultaneously, the material remaining at AS mainly experienced a compression deformation, forming the ASTMAZ. As most of the deformation heat was carried way with the rotating material, the temperature of AS-TMAZ was relative low at this moment.

After rotating around the probe almost once, the material from AS was deposited against the AS-TMAZ. The AS-TMAZ was heated up and compressed further by the deposited material, and then was refined through recrystallization. Fig. 13a shows that AS-TMAZ contained high fraction of LAGBs and low ratio of the twin boundaries, indicating that the grains in the AS- 
TMAZ experienced a further plastic deformation after recrystallization, which was caused by the deposited material as well as the tool shoulder.

Since almost all the material intersecting the probe needed to pass through the RS, the material at the RS of probe experienced high compression force. Under the high compression force, the grains in RS-TMAZ experienced high compression deformation. Fig. 13b shows that high fraction of LAGBs and low ratio of twin boundaries were observed in the RS-TMAZ. This suggested that the temperature in the RS-TMAZ is relative low and insufficient for an extensive development of recrystallization and annealing twins. The low temperature in the RS-TMAZ can be attributed the factor that the MFZ adjacent to RS-TMAZ rotated the shortest distance and generated the lowest deformation heat relative to the rest of the MFZ.

According to this analysis, it is clear that the RS-TMAZ experienced a simple compression deformation at intermediate temperatures. A deformation structure developed in the RS-TMAZ. The AS-TMAZ was compressed at low temperatures first with the approach of probe. After the rotating material was deposited against the AS-TMAZ, the deformed grains was heated up and compressed further by both the hot deposited materials and the tool shoulder. The deformed grains recrystallized at the elevated temperatures. Thus, The AS-TMAZ mainly consisted of fine equiaxed grains.

\section{Conclusions}

The microstructure evolution of the annealed stainless steel during FSW can be deviated into

four stages: (1) Compression deformation, (2) rotation deformation, (3) forge and torsion deformation and (4) annealing.

Stage I: As the material approached the probe, it was compressed, forming CPZ. In the CPZ, high density of LAGB segments generated. Some of the LAGB segments developed in to 
long HAGBs, subdividing the former coarse grains. A volume of fine equiaxed grains generated through DDRX. The twin boundaries inherited from base material have deviated from the exact twin/matrix relationship due to the plastic deformation.

Stage II: The coarse deformed grains in CPZ evolved to fine equiaxed grains mainly through DDRX and twining as the material approached the MFZ. As material rotated around the probe in the MFZ, the fraction of LAGBs reduced, the ratio of twin boundaries increased, the grain size distribution became wider, but the average grain size was fairly constant despite the increase in strain. The B component developed in the MFZ and was sustained in the MFZ with its shear direction being consisted with the local probe rotation. The shear plan of B component maintained approximately 30 deg away from the probe profile.

Stage III: After the material was deposited behind the probe, the grains started to grow at elevated temperatures. The tool shoulder introduced forge and torsion deformation to the material, producing new LAGB segments and disrupting the twin boundaries generated in the MFZ. The B component was weakened.

Stage IV: After the tool shoulder has passed, the material still exposed to high temperatures. Under this annealing condition, the density of LAGBs decreased and new twin boundaries developed. The B component evolved to $\mathrm{C}$ component in this region.

\section{Acknowledgements}

The authors thank the National Science Foundation (under award number 1405508) for financial support of this work.

\section{Reference}

[1] J.Q. Su, T.W. Nelson, R. Mishra, M. Mahoney, Microstructural investigation of friction stir welded 7050-T651 aluminum, Acta Mater. 51 (2003) 713-729 
[2] F.C. Liu, Z.Y. Ma, M.J. Tan, Facilitating basal slip to increase deformation ability in MgMn-Ce alloy by textural reconstruction using friction stir processing, Metall. Mater. Trans. A 44 (2013) 3947-3960.

[3] N.H.B. Schmidt, T.L. Dickerson, J.H. Hattel, Material flow in butt friction stir welds in AA2024-T3, Acta Mater. 54 (2006) 1199-1209.

[4] S. Mironov, T. Onuma, Y.S. Sato, H. Kokawa, Microstructure evolution during friction-stir welding of AZ31 magnesium alloy, Acta Mater. 100 (2015) 301-312.

[5] K.V. Jata, S.L. Semiatin, Continuous dynamic recrystallization during friction stir welding of high strength aluminum alloys, Scripta Mater. 43 (2000) 743-749.

[6] A. Steuwer, M. Dumont, J. Altenkirch, S. Birosca, A. Deschamps, P.B. Prangnell, P.J. Withers, A combined approach to microstructure mapping of an Al-Li AA2199 friction stir weld, Acta Mater. 59 (2011) 3002-3011.

[7] S. Mironov, Y.S. Sato, H. Kokawa, H. Inoue, S. Tsuge, Structural response of superaustenitic stainless steel to friction stir welding, Acta Mater. 59 (2011) 5472-5481.

[8] J.Q. Su, T.W. Nelson, C.J. Sterling, Microstructure evolution during FSW/FSP of high strength aluminum alloys, Mater. Sci. Eng. A 405 (2005) 277-286.

[9] Y.S. Sato, T.W. Nelson, C.J. Sterling, Recrystallization in type 304L stainless steel during friction stirring, Acta Mater. 53 (2005) 637-645.

[10] P.B. Prangnell, C.P. Heason, Grain structure formation during friction stir welding observed by the 'stop action technique', Acta Mater. 53 (2005) 3179-3192.

[11] R.W. Fonda, K.E. Knipling, J.F. Bingert, Microstructural evolution ahead of the tool in aluminum friction stir welds, Scripta Mater. 58 (2007) 343-348.

[12] U.F.H.R. Suhuddin, S. Mironov, Y.S. Sato, H. Kokawa, C.W. Lee, Grain structure evolution during friction stir welding of AZ31 magnesium alloy, Acta Mater. 57 (2009) 5406-5418.

[13] F.C. Liu, T.W. Nelson, In-situ material flow pattern around probe during friction stir welding of austenitic stainless steel, Mater. Des. 110 (2016) 354-364. 
[14] H. Hu, S.R. Goodman, Cube-textured stainless steel and some of its properties, Mater. Sci. Eng. 67 (1984) 143-155.

[15] Y.V. Nesterova, V.V.Rybin, Mechanical twinning and fragmentation of technically pure titanium on developed plastic deformation stage, Phys. Met. Metall. 59 (1985) 395-406.

[16] F.J. Humphreys, M. Hatherly, Recrystallization and related annealing phenomena, second ed., Elsevier, Oxford, 2004, pp 31-31.

[17] H.H. Cho, S.T. Hong, J.H. Roh, H.S. Choi, S.H. Kang, R.J. Steel, H.N. Han, Threedimensional numerical and experimental investigation on friction stir welding processes of ferritic stainless steel, Acta Mater. 61 (2013) 2649-2661.

[18] R. Nandan, G.G. Roy, T.J. Lienert, T. Debroy, Three-dimensional heat and material flow during friction stir welding of mild steel, Acta Mater. 55 (2007) 883-895.

[19] K. Wang, F.C. Liu, P. Xue, D. Wang, B.L. Xiao, Z.Y. Ma, Superplastic constitutive equation including percentage of high-angle grain boundaries as a microstructural parameter, Metall. Mater. Trans. 47A (2015) 546-559.

[20] F.C. Liu, Z.Y. Ma, Contribution of grain boundary sliding in low-temperature superplasticity of ultrafine-grained aluminum alloys, Scripta Mater. 62 (2010) 125-128.

[21] F.C. Liu, P. Xue, Z.Y. Ma. Microstructural evolution in recrystallized and unrecrystallized Al-Mg-Sc alloys during superplastic deformation, Mater. Sci. Eng. A 547 (2012) 55-63.

[22] F.C. Liu, Z.Y. Ma, Achieving high strain rate superplasticity in cast $7075 \mathrm{Al}$ alloy via friction stir processing, J. Mater. Sci. 44 (2009) 2647-2655

[23] Y.S. Li, Y. Zhang, N.R. Tao, K. Lu, Effect of the Zener-Hollomon parameter on the microstructures and mechanical properties of $\mathrm{Cu}$ subjected to plastic deformation, Acta Mater. 57 (2009) 761-772.

[24] C.I. Chang, C.J. Lee, J.C. Huang, Relationship between grain size and Zener-Holloman parameter during friction stir processing in AZ31 Mg alloys, Scripta Mater. 51 (2004) 509-514.

[25] F.C. Liu, Z.Y. Ma, Low-temperature superplasticity of friction stir processed Al-Zn-Mg-Cu alloy, Scripta Mater. 58 (2008) 667-670. 
[26] Z.Y. Ma, F.C. Liu, R.S. Mishra, Superplastic deformation mechanism of an ultrafinegrained aluminum alloy produced by friction stir processing, Acta Mater. 58 (2010) 4693-4704.

[27] X.X. Zhang, B.L. Xiao, Z.Y. Ma, A transient thermal model for friction stir weld part II:

Effects of weld conditions, Metall. Mater. Trans. 42A (2011) 3229-3239.

[28] C. Zener, J.H. Hollomom, Effect of strain rate upon plastic flow of steel, J. Appl. Phys. 15 (1944) 22-32.

[29] H. Hu, Direct observations on the annealing of Si-Fe crystals in the electron microscope, Trans. Metall. Soc. A.I.M.E. 224 (1962) 75-84.

[30] R.W. Fonda, K.E. Knipling, D.J. Rowenhorst, EBSD analysis of friction stir weld texture, JOM 66 (2014) 149-155.

[31] R.W. Fonda, J.F. Bingert, texture variations in aluminum friction stir weld, Scripta Mater. 57 (2007) 1052-1055.

[32] G.R. Canova, U.F. Kocks, J.J. Jonas, Theory of torsion texture development, Acta Metall. 32 (1984) 211-226.

[33] F. Montheillet, M. Chhen, J.J. Jonas, Axial stresses and texture development during the torsion testing of Al, $\mathrm{Cu}$ and $\alpha-\mathrm{Fe}$, Acta Metall. 32 (1984) 2077-2089.

[34] F. Montheillet, P. Gilormini, J.J. Jonas, Relation between axial stresses and texture development during torsion testing: a simplified theory, Acta Metall. 33 (1985) 705-717.

[35] M.G. Stout, J.S. Kallend, U.F.Kocks, M.A. Przystupa, A.D. Rollett, Material dependence of deformation texture development in various deformation modes. In Eighth international conference on textures of materials, (1988) 479-484.

[36] D.A. Hughes, H.R. Wenk, The effect of stacking fault energy on the textures of nikel-cobalt solid solutions at large strains. In Eighth international conference on textures of materials, (1988) 455-460.

[37] K Sekien, P. Van Houtte, J. Gil Sevillano, E. Aernoudt, the transition of torsion deformation textures in fcc metals. In Sixth international conference on textures of materials, (1981) 396-407. 